\title{
AJUSTE DE MODELO LINEAR DE TENDÊNCIA E PREVISÃO PARA SÉRIES DE PRODUÇÃO DE LEITE
}

\author{
Matheus Silva de Oliveira ${ }^{1}$ \\ Maristela de Oliveira Bauer ${ }^{2}$ \\ Juliana Di Giorgio Giannotti ${ }^{3}$
}

Resumo: Utilizou-se a metodologia de séries temporais aplicada à série anual de produção de leite presente na Pesquisa Pecuária Municipal (PPM) do Instituto Brasileiro de Geografia e Estatística (IBGE), no período de 1974 a 2014, com o objetivo de ajustar um modelo de tendência e previsão para o Brasil, a região Sudeste e o estado do Espírito Santo. Os modelos ajustados para as três séries de dados apresentaram coeficiente de determinação entre $90 \%$ e 97\%, a tendência encontrada foi linear e crescente e a previsão mostra continuidade desta tendência de crescimento na produção. Pode-se inferir que os modelos obtidos são adequados para indicar a tendência e previsão dos dados nas três regiões em estudo. Palavras-chave: Séries históricas; Modelos probabilísticos; Estatísticas leiteiras.

\footnotetext{
1 Graduando em Engenharia Química CCAE/UFES, Brasil. E-mail: mths_01@hotmail.com.

2 Professora do Departamento de Engenharia Rural, CCAE/UFES, Brasil. E-mail: marisufes@gmail.com.

3 Professora do Departamento de Engenharia Rural, CCAE/UFES, Brasil. E-mail: jggiannotti@gmail.com.
} 